\title{
Periodontal disease as an additional risk factor associated with preterm birth in Mexico: a case-control study
}

\author{
J. Jesús Pérez-Molina, ${ }^{1 *}$ María Janeth González-Cruz, ${ }^{1}$ J. Guadalupe Panduro-Barón, ${ }^{2}$ \\ Luz Patricia Santibáñez-Escobar, ${ }^{3}$ Norma Argelia Quezada-Figueroa ${ }^{4}$ and Martín Bedolla-Barajas ${ }^{5}$ \\ ${ }^{1}$ Hospital Civil de Guadalajara "Dr. Juan I. Menchaca", Pediatrics Division, Neonatology Department; ${ }^{2}$ Hospital Civil de Guadalajara "Dr. Juan I. \\ Menchaca", Obstetrics and Gynecology Division; ${ }^{3 H o s p i t a l ~ C i v i l ~ d e ~ G u a d a l a j a r a ~ " D r . ~ J u a n ~ I . ~ M e n c h a c a ", ~ D e p a r t m e n t ~ o f ~ M a x i l l o f a c i a l ~ S u r g e r y ; ~}$ \\ ${ }^{4}$ Universidad de Guadalajara, University Center of Health Sciences, Department of Human Reproduction, Growth and Children Development Clinics; \\ ${ }^{5}$ Hospital Civil de Guadalajara "Dr. Juan I. Menchaca", Department of Allergy and Clinical Immunology. Guadalajara, Jalisco, Mexico
}

\begin{abstract}
Introduction: Substances related to microorganisms involved in periodontal disease can reach the maternal-fetal interface via the hematogenous route and stimulate uterine contractility. Objective: To determine the association between periodontal disease and preterm birth. Method: Case-control study in 343 preterm and 686 full-term pregnant women. Gestational age was calculated based on the date of the last menstrual period and confirmed with Capurro and Ballard methods. Periodontal disease was diagnosed according to the depth of the space between the tooth root and the gum. The association was measured with logistic regression. Results: Maternal age of the cases was $23.8 \pm 6.7$ years, and $23.2 \pm 6.7$ in the controls. Periodontal disease was present in $66.8 \%$ of cases and $40.5 \%$ of controls. The factors associated with preterm birth were periodontal disease (Odds ratio $[O R]=2.26)$, history of preterm birth $(O R=4.96)$, unplanned pregnancy $(O R=2.15)$ poor prenatal control $(O R=2.53)$, urinary tract infection $(O R=2.22)$, preeclampsia $(O R=4.49)$, premature rupture of membranes $(O R=2.59)$ and caesarean section delivery $(O R=9.15)$. Conclusion: Periodontal disease in pregnancy was an independent risk factor for preterm birth.
\end{abstract}

KEY WORDS: Preterm birth. Periodontal disease. Risk factors.

\section{Introduction}

A preterm birth $(\mathrm{PB})$ is that which is delivered prior to 37 weeks of gestation or at 259 days from the first day of the last menstrual period (LMP). ${ }^{1}$

PB global incidence is around 15 million PBs per year and, in the United States, it is the main cause of neonatal morbidity and mortality. ${ }^{2}$ Survivors experience approximately half the neurodevelopmental disorders that occur in childhood, ${ }^{1}$ and the social costs resulting from medical and educational expenditure and loss of productivity amount to 26.2 billion dollars annually. ${ }^{2}$
In the United States, the PB rate is 12 to $13 \%$, while in Europe and other developed countries, frequency has been estimated at 5 to $9 \% .^{3}$ In a study conducted at Hospital Civil de Guadalajara "Dr. Juan I. Menchaca" in Guadalajara, Jalisco, where the research was carried out, the PB rate was $6.9 \%{ }^{4}$

Preterm labor is a syndrome that can be triggered by multiple mechanisms, including intrauterine and extrauterine infections, inflammation, ischemia, uteroplacental hemorrhage, uterine overdistention, stress and immune processes. Several maternal characteristics have also been associated with higher frequency, including demographic, nutritional and psychological variables. ${ }^{3}$
Gac Med Mex. 2019;155:131-136

Contents available at PubMed www.gacetamedicademexico.com 
Periodontal disease (PD) is a chronic inflammatory condition that involves the soft and hard tissues surrounding the tooth, as well as the periodontal ligament, bone and cement, mostly due to gram-negative and anaerobic microorganisms and substances thereof related, such as pro-inflammatory cytokines and lipopolysaccharides, which can reach the maternal-fetal interface via the hematogenous route and stimulate uterine contractility. ${ }^{5,6}$

There are studies that have found an association between $\mathrm{PD}$ and $\mathrm{PB} ;{ }^{6-10}$ however, others have not documented it. ${ }^{11-13}$

At each geographical region, there may be local factors with the capacity to modify the relationship between $\mathrm{PD}$ and $\mathrm{PB}$ frequency and, therefore, the purpose of this research was to determine this association in a public hospital located in western Mexico.

\section{Method}

A case-control study was carried out. ${ }^{14}$ The study population were mother-child dyads under the care of Hospital Civil de Guadalajara "Dr. Juan I. Menchaca", which provides health services to urban, open and low-income population of the metropolitan area of Guadalajara, in western Mexico, from May 2011 to June 2012.

The sample was constituted with all consecutively included mother-child dyads with alive children of 24 to 36 weeks of gestation (WOG) (cases), and two mother-child dyads with alive children of 37 to 41 WOG per case (controls), with the latter being selected in a simple random form among the population of full-term births.

The sample size was calculated with an alpha error of $0.05 \%$, a beta error of $20 \%$ and a ratio of two controls per case. To include the frequency of exposure to PD and the possible confounding variables with lower exposure differential between cases and controls, the poor prenatal care variable was considered, ${ }^{6}$ which in PBs was $11 \%$ and in full-term births $3 \%$, with $20 \%$ added for possible exclusions; thus, the calculation suggested 154 cases and 308 controls.

The dependent variable was PB (24-36 WOG) and the independent variable was PD. PD was assumed to be present when, after complete oral examination, four or more teeth had at least one site with $\geq 4 \mathrm{~mm}$ depth and clinical loss of bone or soft tissue $\geq 3 \mathrm{~mm},{ }^{15}$ as measured with PerioWise ${ }^{\circledR}$ (Premier) disposable periodontal probe. PD intensity was measured as follows:

- Mild degree, when four or more teeth had at least one site with proven depth $\geq 4 \mathrm{~mm}$ and at least one tooth with attachment loss $\geq 3 \mathrm{~mm}$ (loss of bone or soft tissue).

- Moderate degree, when four or more teeth had at least one site with proven depth $\geq 4 \mathrm{~mm}$ and at least one tooth with attachment loss $\geq 4 \mathrm{~mm}$ (loss of bone or soft tissue).

- Severe degree, when four or more teeth had at least one site with proven depth $\geq 4 \mathrm{~mm}$ and at least one tooth with attachment loss $\geq 5 \mathrm{~mm}$ (loss of bone or soft tissue). ${ }^{15}$

Gestational age was calculated based on the days elapsed since LMP, obtained by direct interview. When neonates had > 29 WOG, newborns (NBs) gestational age was assessed with the Capurro method, ${ }^{16}$ and in NBs with $\leq 29$ WOG, with the Ballard test. ${ }^{17}$ When there was a difference greater than two weeks between gestational age calculated by LMP and measured by Capurro or Ballard methods, and when the mother failed to remember the LMP, gestational age obtained by Capurro or Ballard methods was deemed definitive.

To measure the independent and dependent variables, one of the researchers was trained and standardized until almost perfect agreement was obtained between two observers: ${ }^{18}$ to diagnose PD as present or absent, it was standardized with a certified dentist (kappa coefficient $=0.927)$ for measurements $\pm 1 \mathrm{~mm}$ between each pair of examiners. To quantify WOG and diagnose PB as present or absent, the procedure was standardized with a certified neonatologist to perform the Capurro (kappa coefficient $=0.940$ ) and Ballard evaluations (kappa coefficient $=0.934$ ) .

The research data was prolectively collected. In addition to measuring the independent and dependent variables, first-hand information was also obtained by direct interviews with the mothers within the first 24 hours of the NB delivery, including age, LMP, history of preterm birth not due to medical indications, prenatal care, socioeconomic status, demographic data, planned pregnancy, use of drugs, sexual partners, sexual abuse and diseases during pregnancy.

On the same day of the interview, information was collected from the clinical record regarding the type of birth, spontaneous rupture of amniotic membranes prior to the start of labor, urine culture results to diagnose urinary tract infection, diseases during pregnancy and relevant obstetric data.

Prenatal care was adequate when the mothers had at least five prenatal control visits with the following schedule: the first one, within the initial 12 weeks, the second one, between week 22 and 24, the third one, 
Table 1. Demographic, medical and obstetric characteristics of the study groups

\begin{tabular}{|c|c|c|c|c|c|c|}
\hline \multirow[t]{2}{*}{ Variables } & \multicolumn{2}{|c|}{ Preterm NBs $n=343$} & \multicolumn{2}{|c|}{ Full-term NBs n = 686} & \multirow[t]{2}{*}{ OR $(95 \%$ Cl) } & \multirow[t]{2}{*}{$p$} \\
\hline & 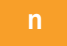 & $\%$ & $n$ & $\%$ & & \\
\hline Marital status* & 229 & 66.8 & 458 & 66.8 & $1(0.75-1-33)$ & 0.999 \\
\hline Occupation $^{\dagger}$ & 322 & 95.9 & 634 & 92.4 & $1.26(0.74-2.12)$ & 0.390 \\
\hline Socioeconomic status ${ }^{\ddagger}$ & 155 & 45.2 & 375 & 54.7 & $0.68(0.53-0.89)$ & 0.002 \\
\hline Smoking\& & 24 & 7.0 & 51 & 7.4 & $0.94(0.55-1.59)$ & 0.799 \\
\hline Alcohol consumption\& & 20 & 5.8 & 28 & 4.1 & $1.46(0.78-2.72$ & 0.209 \\
\hline Use of illicit drugs\& & 9 & 2.6 & 9 & 1.3 & $2.03(0.73-5.61)$ & 0.130 \\
\hline Sexual partners ${ }^{\bullet}$ & 16 & 4.7 & 24 & 3.5 & $1.35(0.67-2.69)$ & 0.361 \\
\hline Sexual abuse ${ }^{\&}$ & 8 & 2.3 & 12 & 1.7 & $1.34(0.50-3.56)$ & 1.34 \\
\hline History of PTNB\& & 49 & 14.3 & 30 & 4.4 & $3.64(2.21-6.02)$ & $<0.001$ \\
\hline Unplanned pregnancy\& & 119 & 34.7 & 141 & 20.5 & $2.05(1.52-2.77)$ & $<0.001$ \\
\hline Primigravida" & 129 & 37.6 & 265 & 38.6 & $0.96(0.73-1.26)$ & 0.750 \\
\hline Multiple pregnancy** & 40 & 11.7 & 5 & 0.7 & $17.98(6.71-52.3)$ & $<0.001$ \\
\hline Prenatal carett & 191 & 55.7 & 283 & 41.2 & $1.79(1.37-2.35)$ & $<0.001$ \\
\hline UTI during pregnancy\& & 82 & 23.8 & 113 & 16.5 & $1.59(1.16-2.19)$ & $<0.001$ \\
\hline Preeclampsia ${ }^{\&}$ & 21 & 6.1 & 9 & 1.3 & $4.91(2.22-10.83)$ & $<0.001$ \\
\hline Diabetes mellitus\& & 8 & 2.3 & 4 & 0.6 & $4.07(1.22-13.6)$ & 0.006 \\
\hline Periodontal disease ${ }^{\&}$ & 229 & 66.8 & 278 & 40.5 & $2.95(2.23-3.90)$ & $<0.001$ \\
\hline $\mathrm{SMR}^{\&}$ & 28 & 8.2 & 16 & 2.3 & $3.72(1.91-7.31)$ & $<0.001$ \\
\hline Delivery by cesarean section & 268 & 78.1 & 206 & 30.0 & $8.33(6.08-11.42)$ & $<0.001$ \\
\hline \multicolumn{7}{|c|}{ 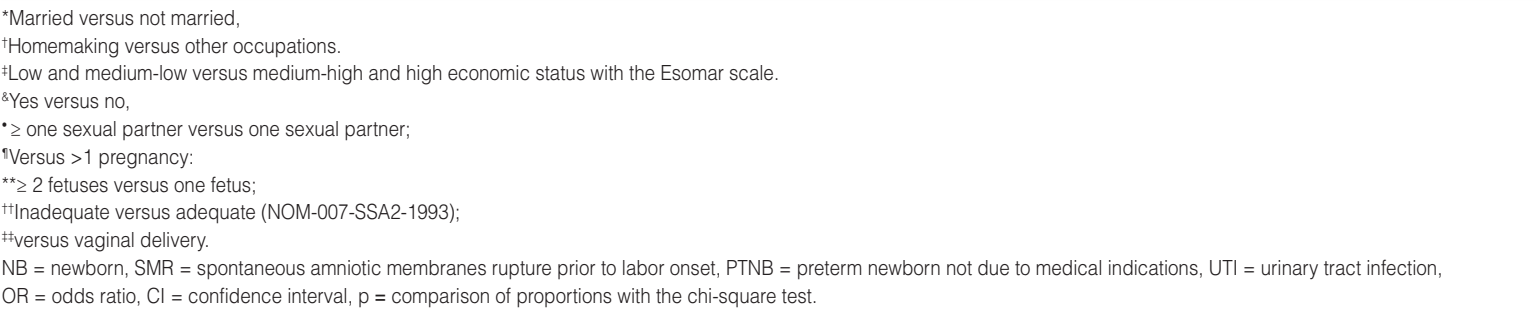 } \\
\hline
\end{tabular}

between week 27 and 29, the fourth, between week 33 and 35 , and the fifth one at week 36 of gestation. ${ }^{19}$ This schedule was adjusted to the duration of gestation for each mother-preterm child dyad.

The socioeconomic status was assessed using the Esomar scale, ${ }^{20}$ which takes into account the occupation of the head of the family, economic income, level of education and housing characteristics.

Mother-child dyads with incomplete information to determine if PD was a risk factor for PB were eliminated from the investigation. An information collection and capture pilot test was carried out prior to the definitive records in order to detect and correct errors and inconsistent data was not included in the definitive database.
Quantitative variables mean and standard deviation were calculated and compared with Student's t-test for two independent samples; qualitative variables were described with proportions and compared with the chisquare test or Fisher's exact test, as necessary. The risk between PD with $\mathrm{PB}$ and the confounding effect was measured with odds ratios (OR) by logistic regression with the forward conditional method. Goodness of fit of the model was verified with the Hosmer and Lemeshow test. In all calculations, confidence interval was $95 \%(95 \% \mathrm{Cl})$. The analyses were carried out with the statistical program SPSS, version 22.0.

The research was approved by the research and ethics committees of the host hospital (registry 1101/11). 
Table 2. Logistic regression analysis with preterm birth as the outcome variable in single pregnancies and possible confounding covariates

\begin{tabular}{|c|c|c|c|c|c|c|}
\hline \multirow[t]{2}{*}{ Covariates } & \multicolumn{3}{|c|}{ Bivariate analysis } & \multicolumn{3}{|c|}{ Adjusted model** } \\
\hline & OR & $95 \% \mathrm{Cl}$ & $p$ & OR & $95 \% \mathrm{Cl}$ & $p$ \\
\hline Periodontal disease* & 2.95 & $2.23-3.90$ & $<0.001$ & 2.25 & $1.61-3.14$ & $<0.001$ \\
\hline $\mathrm{SMR}^{*}$ & 3.72 & $1.91-7.31$ & $<0.001$ & 2.59 & $1.23-5.47$ & 0.012 \\
\hline History of PTNB* & 3.64 & $2.21-6.02$ & $<0.001$ & 4.96 & $2.75-8.95$ & $<0.001$ \\
\hline Unplanned pregnancy* & 2.05 & $1.52-2.77$ & $<0.001$ & 2.15 & $1.49-3.12$ & $<0.001$ \\
\hline Prenatal care $^{\dagger}$ & 1.79 & $1.37-2.35$ & $<0.001$ & 2.53 & $1.80-3.56$ & $<0.001$ \\
\hline UTI during pregnancy* & 1.59 & $1.16-2.19$ & $<0.001$ & 2.22 & $1.46-3.35$ & $<0.001$ \\
\hline Preeclampsia* & 4.91 & $2.22-10.83$ & 0.001 & 4.49 & $1.81-11.10$ & 0.001 \\
\hline Diabetes mellitus* & 4.07 & $1.22-13.8$ & 0.006 & 3.43 & $0.81-14.49$ & 0.093 \\
\hline Delivery by cesarean section* & 8.33 & $6.08-11.42$ & $<0.001$ & 9.15 & $6.41-13.08$ & $<0.001$ \\
\hline
\end{tabular}

The mothers signed a written informed consent to participate in the study.

\section{Results}

Complete information was obtained in 343 mother-alive preterm child dyads and 686 mother-alive fullterm child dyads.

Mean age of the mothers in the mother-alive preterm child dyads was $23.8 \pm 6.7$ years and in the mother-alive full-term child dyads, $23.2 \pm 6.0$ years $(p=0.143)$. Family monthly income was $4654 \pm 2016$ and $4378 \pm 2190$ Mexican pesos $(p=0.051)$ and the level of education was $7.9 \pm 3.0$ and $7.6 \pm 2.8$ years of schooling $(p=0.154)$, respectively. The Capurro and Ballard ratings-corrected gestational age was $33.5 \pm 2.7$ weeks in the group of cases and $39.1 \pm 1.1$ weeks in the control group. The kurtosis and asymmetry indices of the aforementioned variables suggested a normal distribution.

The frequency of PD in the group of cases was $229 / 343(66.8 \%)$, and it was of mild intensity in $165 / 229$ (72 \%), moderate in 60/229 (26.2 \%) and severe intensity in $4 / 229(1.8 \%)$. In the control group, the frequency of PD was 278/686 (40.5\%), and it was of mild intensity in $268 / 278$ (96.4 \%), moderate in 10/278 (3.6\%) and there were no severe cases.

In relation to dental health habits during pregnancy, 294/343 (87.7 \%) cases and 524/686 (76.4\%) controls never had a dental check-up.

In the bivariate analysis, factors such as a history of preterm delivery not due to medical indications, unplanned pregnancy, multiple pregnancy, inadequate prenatal control, urinary tract infection during pregnancy, preeclampsia, diabetes mellitus, spontaneous rupture of amniotic membranes prior to the onset of labor, delivery by cesarean section and presence of periodontal disease were more common in the cases $(p<0.05)$ (Table 1).

The frequency of low and medium-low socioeconomic status was lower in the group of cases and the frequencies of smoking, alcohol consumption and illicit drug use during pregnancy were similar in the case and control groups. Maternal marital status, occupation, having more than one sexual partner and a history of sexual abuse were also similarly distributed in both groups (Table 1).

To determine whether PD was a risk factor for PB and to assess the effect of the studied covariates, multiple pregnancies were first excluded and then a multivariate analysis by logistic regression with the forward conditional method was used for single pregnancies. Periodontal disease $(O R=2.25, p<0.001)$, previous history of preterm delivery not due to medical indications $(\mathrm{OR}=4.96, \mathrm{p}<0.001)$, unplanned pregnancy $(\mathrm{OR}=2.15, \mathrm{p}<0.001)$, poor prenatal care $(\mathrm{OR}=2.53$, $p<0.001$ ), urinary tract infection during pregnancy $(\mathrm{OR}=2.22, \mathrm{p}<0.001)$, preeclampsia $(\mathrm{OR}=4.49$, p 0.001), spontaneous amniotic membranes rupture prior to labor onset $(\mathrm{OR}=2.59, \mathrm{p}<0.012)$ and delivery by cesarean section $(O R=9.15, p<0.001)$ were documented to remain as risk factors for preterm birth, while the association with diabetes mellitus during pregnancy disappeared (Table 2). 


\section{Discussion}

The present study shows that periodontal disease was an independent risk factor for preterm birth additional to the risk factors traditionally associated with $\mathrm{PB},{ }^{1-3,21}$ such as a previous history of PB not due to medical indications, poor prenatal care, urinary tract infection during pregnancy, preeclampsia, spontaneous rupture of amniotic membranes prior to labor onset and cesarean section delivery.

The association between PD and PB was first suggested in the United States in 1996 by Ofenbacher et al. $^{6}$ in a case-control study (OR $=7.5,95 \%$ Cl: 1.9-28.8) and confirmed with cohort designs by Jeffcoat et al. al. ${ }^{7}(\mathrm{RR}=4.5,95 \% \mathrm{Cl}: 2.2-9.2)$ and Ofenbacher et al. ${ }^{8}(\mathrm{RR}=2.0,95 \% \mathrm{Cl}: 1.2-3.2)$. Similarly, with case-control designs, Siqueira et al. ${ }^{9}$ also reported this association in Brazil ( $\mathrm{OR}=1.77 ; 95 \% \mathrm{Cl}: 1.12-2.59)$, Pulikottil Shaju et al. ${ }^{10}$ did it in India (OR = 2.94; IC 95 $\%: 1.9-4.6)$ and Mega et al. ${ }^{22}$ in Kosovo (OR $=3.4 ; 95$ $\% \mathrm{Cl}$ 1.6-7.9). In addition, in Chile, López et al. ${ }^{23}$ demonstrated in a clinical trial that $\mathrm{PD}$ is a risk factor for $\mathrm{PB}$ (OR $=4.70 ; 95 \% \mathrm{Cl}: 1.29-17.13)$.

On the other hand, no association has been found between PD and higher PB frequency in different investigations, such as those conducted by Wood et al. in Canada, ${ }^{11}$ Moore et al. in the United Kingdom ${ }^{24}$ and Lohsoonthom et al. in Thailand ${ }^{12}$ with case-control designs, as well as Calabrese et al. ${ }^{13}$ in a cross-sectional study conducted in Italy.

In most reviewed studies, ${ }^{6,8-13}$ the PD diagnosis in the mothers was established shortly after the NB's delivery, the same way it was carried out in the present investigation, using diagnostic criteria based on clinical signs of inflammation (presence of teeth with at least one site with $\geq 4 \mathrm{~mm}$ depth and clinical loss of bone or soft tissue $\geq 3 \mathrm{~mm}),{ }^{15}$ similar to those reported by other investigators. ${ }^{6-11,13}$ In addition, the strength of association between PD and PB found in this study $(\mathrm{OR}=2.25 ; 95 \% \mathrm{Cl}: 1.61-3.14)$ was also consistent with those reported by Ofenbacher et al., ${ }^{8}$ Siqueira et al. ${ }^{9}$ and Pulikottil Shaju Jacob et al. ${ }^{10}$

In a systematic review by Xiong et al. ${ }^{5}$ about PD and pregnancy adverse outcomes, it is suggested that these may be worse in low socioeconomic strata with poor access to dental health care, as it occurred in the present investigation, where $89 \%$ of women of the cases and $76 \%$ of the controls never had a dental check-up.

Furthermore, Xiong et al. ${ }^{5}$ and Lohsoonthom et al. ${ }^{12}$ refer that studies carried out in Europe, where citizens have universal dental health, have found no association between PD and PB.

Documenting the role of $\mathrm{PD}$ as an independent risk factor for PB is important because there are few publications that have studied this relationship in Latin America.

$\mathrm{Zi}$ et al. ${ }^{25}$ refer that PD has been proposed to be related to PB because microorganisms and their products originating from subgingival sites can reach the amniotic fluid via the hematogenous route and trigger the pro-inflammatory pathway in the placenta and fetal tissues. In addition, gingival tissue pathogens contribute to the release of additional mediators that are systemically disseminated and, this way, an inflammatory environment is created, which activates labor onset and restricts fetus growth.

One limitation of this study was that gestational age was not determined with serial ultrasounds in all pregnancies, in part due to the retrospective nature of the research design. To increase gestational age assessment accuracy by LMP, it was corrected with the Capurro and Ballard methods. It should be noted that the case-control design does not allow to document causal association; however, the demonstration that $\mathrm{PD}$ was an independent risk factor for PB allows preventive measures to be undertaken, especially in vulnerable groups such as women of childbearing age with limited access to dental care.

For all the above, the present study allows to conclude that PD is a preventable risk factor for PB and reinforces the importance of its prevention, detection and treatment before and during pregnancy.

\section{References}

1. Ananth CV, Vintzileos AM. Epidemiology of preterm birth and its clinical subtypes. J Matern Fetal Neonatal Med. 2006;19:773-782.

2. Purish SE, Gyamfi-Bannerman C. Epidemiology of preterm birth. Semin Perinatol. 2017:41:387-393.

3. Goldenberg RL, Culhane JF, lams JD, Romero R. Epidemiology and causes of preterm birth. Lancet. 2008;371:75-84.

4. Pérez-Molina J, Quezada-López C, Panduro-Barón G, Castro-Hernández JF. Factores de riesgo materno asociados con muerte fetal en nacimientos pretérmino en un hospital público del occidente de México. Rev Invest Clin. 2012;64:330-335.

5. Xiong X, Bueckens P, Fraser WD, Beck J, Offenbacher S. Periodontal disease and adverse pregnancy outcomes: a systematic review. BJOG. 2006:113:135-143

6. Offenbacher S, Katz V, Fertik G, Collins J, Boyd D, Maynor G, et al. Periodontal infection as a possible risk factor for preterm low birth weight. J Periodontol. 1996;67:1103-1113.

7. Jeffcoat MK, Geurs NC, Reddy MS, Cliver SP, Goldenberg RL, Hauth JC. Periodontal infection and preterm birth: results of a prospective study. J Am Dent Assoc. 2001;132:875-880.

8. Ofenbacher S, Boggess KA, Murtha AP, Jared HL, Lieff S, McKaig RG, et al. Progressive periodontal disease and risks of very preterm delivery. Obstet Gynecol. 2006;107:29-36.

9. Siqueira FM, Cota LO, Costa JE, Haddad JP, Lana AM, Costa FO. Intrauterine growth restriction, low birth weight, and preterm birth: adverse pregnancy outcomes and their association with maternal periodontitis. J Periodontol. 2007;78:2266-2276. 
10. Pulikottil-Shaju J, Nath S. Periodontitis among poor rural Indian mothers increases the risk of low birth weight babies: a hospital-based case control study. J Periodontal Implant Sci. 2014;44:85-93.

11. Wood S, Frydman A, Cox S, Brant R, Needoba S, Eley B, et al. Periodontal disease and spontaneous preterm birth: case control study. BMC Pregnancy Childbirth. 2006;6:24.

12. Lohsoonthron V, Kungsadalpipob K, Chanchareonsook P, Limpongsanurak S, Vanichjakvong O, Sutdhibhisal S, et al. Is maternal periodontal disease a risk factor for preterm birth? Am J Epidemiol. 2009;169:731-739.

13. Calabrese N, Calabrese A, Nibali L, Rosati A, Fiengo S, Di-Renzo GC Is there any association between periodontitis and preterm low birth weight? J Matern Fetal Neonatal Med. 2010;23:1288-1293.

14. Newman TB, Browner WS, Cummings SR, Hulley SB. Designing an observational study: cross-sectional and case-control studies. En: Hulley SB, Cummings SR, Browner WS, Grady D, Hearst N, Newman TB, editores. Designing clinical research an epidemiologic approach. EE. UU.: Lippincott Williams \& Wilkins; 2001

15. Highfield J. Diagnosis and classification of periodontal disease. Aust Dent J. 2009;54:S11-S26.

16. Capurro H, Konichezky S, Fonseca D, Caldeyro-Barcia R. A simplified method for diagnosis of gestational age in the newborn infant. J Pediatr. 1978:93:120-122.

17. Ballard JL, Khoury JC, Wedif K, Wang L, Eilers-Walsman BL, Lipp R. New Ballard score, expanded to include extremely premature infants. J Pediatr. 1991;119:417-423.
18. Cerda J, Villarroel L. Evaluación de la concordancia inter-observador en investigación pediátrica: coeficiente de Kappa. Rev Chil Pediatr. 2008;79:54-58.

19. Norma Oficial Mexicana NOM-007-SSA2-1993, atención de la muje durante el embarazo, parto y puerperio y del recién nacido. Criterios y procedimientos para la prestación del servicio. México: Diario Oficial de la Federación 1994 Oct 31.

20. Adimark. El nivel socio económico Esomar. Manual de Aplicación. Chile; 2000.

21. Pérez-Molina JJ, Cobián-López B, Silva-Maciel CA. Factores de riesgo materno y nacimiento pretérmino en un hospital público del occidente de México. Ginecol Obstet Mex. 2004;72:142-149.

22. Meqa K, Dragidella F, Disha M, Sllamniku-Dalipi Z. The association between periodontal disease and preterm low birthweight in Kosovo. Acta Stomatol Croat. 2017;51:33-40.

23. López NJ, Smith PC, Gutierrez J. Periodontal therapy may reduce the risk of preterm low birth weight in women with periodontal disease: a randomized controlled trial. J Periodontol. 2002;73:911-924

24. Moore S, Randhawa M, Ide M. A case-control study to investigate an association between adverse pregnancy outcome and periodontal disease. J Clin Periodontol. 2005;32:1-5.

25. Zi MY, Longo PL, Bueno-Silva B, Mayer MP. Mechanisms involved in the association between periodontitis and complications in pregnancy. Front Public Health. 2015;29:2:290. 